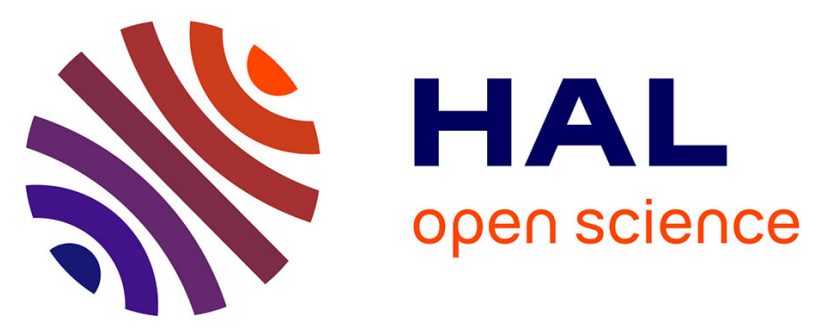

\title{
Creation, Transfer, and Diffusion of Innovation in Organizations and Society: Information Systems Design Science Research for Human Benefit
}

John R. Venable, Jan Pries-Heje, Deborah Bunker, Nancy L. Russo

\section{- To cite this version:}

John R. Venable, Jan Pries-Heje, Deborah Bunker, Nancy L. Russo. Creation, Transfer, and Diffusion of Innovation in Organizations and Society: Information Systems Design Science Research for Human Benefit. IFIP WG 8.2/8.6 InternationalWorking Conference on Human Benefit through the Diffusion of Information Systems Design Science Research, Mar 2010, Perth, Australia. pp.1-10, 10.1007/9783-642-12113-5_1. hal-01054615

\section{HAL Id: hal-01054615 \\ https://inria.hal.science/hal-01054615}

Submitted on 7 Aug 2014

HAL is a multi-disciplinary open access archive for the deposit and dissemination of scientific research documents, whether they are published or not. The documents may come from teaching and research institutions in France or abroad, or from public or private research centers.
L'archive ouverte pluridisciplinaire HAL, est destinée au dépôt et à la diffusion de documents scientifiques de niveau recherche, publiés ou non, émanant des établissements d'enseignement et de recherche français ou étrangers, des laboratoires publics ou privés.

\section{(ㄷ)(i)}

Distributed under a Creative Commons Attribution| 4.0 International License 


\title{
1 CREATION, TRANSFER, AND DIFFUSION OF INNOVATION IN ORGANIZATIONS AND SOCIETY: Information Systems Design Science Research for Human Benefit
}

\author{
John R. Venable \\ Curtin University of Technology \\ Perth, Western Australia \\ Jan Pries-Heje \\ Roskilde University \\ Roskilde, Denmark \\ Deborah Bunker \\ University of Sydney \\ Sydney, Australia \\ Nancy L. Russo \\ Northern Illinois University \\ DeKalb, Illinois, USA
}

\begin{abstract}
Design science research is a way of creating and studying new technological phenomena, where the understanding comes from inventing, designing, and building new forms of solutions to problems. It has been touted as a new means for the IS field to improve its relevance as the resulting design artifact(s) can directly be used to solve relevant problems. DSR is different from other types of research in its focus on building artifacts and learning from the use and application of the artifacts. It is different in that it engages reality in a way that no descriptive or observational research method can. DSR shares the iterative process with action research but can take place in a laboratory without any involvement of users as researchers (Iivari and Venable 2009).
\end{abstract}


Herbert Simon (1996) defined the science of design as the study of the artificial and properly "the way in which that adaptation of means to environments is brought about" (p. 113). Melding science with design provides a means for designing at higher levels of abstraction, designs that are more universal and address a general class of problems rather than a single, unique design problem. In their seminal papers on DSR, Nunamaker et al. (1991), Walls et al. (1992), and March and Smith (1995) laid the foundation for DSR. The consolidation of DSR into mainstream Information Systems research came with Hevner et al.'s (2004) article in MIS Quarterly. In information systems, Vaishnavi and Kuechler (2004) define design science research as "the analysis of the use and performance of designed artifacts to understand, explain and very frequently to improve on the behavior of aspects of Information Systems." Central to these notions is the design of an artifact that is meant to have a presence in the real world. This artifact could be conceived as a construct, a model, a method, or a material instantiation (March and Smith 1995).

The present conference expands on DSR research approaches in IS in three key areas. First, the conference assumes that designing and developing a new technology without also considering the transfer, diffusion, and adoption of that new technology risks producing research that is irrelevant. Both design practice and DSR projects are conducted within an organizational and societal environment, but DSR outcomes (artifacts) must be diffused and adopted into a broad variety of organizational and societal settings. While the importance of such issues has long been the concern of both IFIP Working Groups 8.2 and 8.6, the relationship to DSR has heretofore not explicitly been considered. Bunker and Campbell (2005) have suggested that DSR has been predominantly concerned with building and evaluating artifacts aimed at achieving humandefined goals (Simon 1996), the operationalization of which is affected by contextual complexity. Adoption and diffusion are particularly important to the success of DSR in the context of information systems, due to the complex interactions of design artifacts with social and organizational contexts. Understanding of implementation context is critical to the appropriate design and use of artifacts (March and Smith 1995).

Second, the conference considers that there is a need to emphasize research in which new technologies (e.g., information systems) are designed expressly for human benefit. This theme is one that is well established in IFIP WG 8.2, for example the theme of the 1987 IFIP WG 8.1 and 8.2 Joint Working Conference addressed "Information Systems Development for Human Progress in Organizations" (Klein and Kumar 1987). As they are considered in the current conference, technologies for human benefit are concerned with improving the human condition, for example, by improving the quality of working life, improving health, improving the environment, reducing poverty, improving social conditions, or improving participation in and service provision by government or not-orprofit organizations. Until now, the emphasis on DSR in the IS field has been on meeting business needs (as in Hevner et al. 2004) - that is, on the development of new technologies that are primarily aimed at enabling increased business profit. The choices of goals and problems addressed by DSR, and who is entitled to make those choices, are seminal and should be examined critically. For example, Venable (2009) suggests that the critical systems heuristics framework (Ullrich 1981, 1987, 2002) could be used to guide proper identification of stakeholders and the selection of problem domain and 
system boundaries when conducting design science research. In our view, DSR cannot and should not ignore such concerns and a greater proportion of design science research, including that conducted in the IS field, should focus on human benefit (not-for-profit) rather than purely on business (for-profit). Much of the public policy debate and creation, which is so critical to resourcing of the design of IS artifacts for human benefit (i.e., IS and communications infrastructure and policy encouraging adoption practices ), is directly related to human benefit and social outcomes. Bunker and Campbell, for example, in their examination of a public consultation process in the development of a B2G online authentication framework using the DSR-based approach of perspectival punctuated action (PPA), ask how we get good policy, which leads to the more pressing question: how do we get good policy design? PPA is based on distinct decision-making configurations of intelligence, choice, and design by extending Boland's (2002) articulation of Simon's (1977) decision-making theory.

Third, design (and DSR) is informed by organizational and societal needs, is conducted in an organizational and societal environment, is diffused and adopted into organizational and societal settings, has organizational and societal consequences, and is (ideally) evaluated for how well it works and solves problems in the real (organizational and societal) world. Therefore, IS research needs to take a (more) holistic perspective, which integrates DSR and behavioral research in the creation of the IS artifact. Venable (2006) suggests that the core activity of DSR, technology invention and design, should be integrated with two other main activities in the field of applied research: problem diagnosis (i.e., understanding the causes and consequences of problems) and technology evaluation (i.e., understanding whether technologies are efficient, effective or efficacious - and why). The current emphasis in DSR is on design and evaluation (only) as the key activities (Hevner et al. 2004; March and Smith 1995). Baskerville et al. $(2007,2009)$ recommend the development and use of a soft design science approach to realistically address organizational and societal issues in DSR.

While software and hardware are regarded as the core "working" artifacts in information systems and technology (Orlikowski and Iacono 2001; Weber 2003), there are other artifacts that are also important components in the creation of innovative ITS. These artifacts are constructs, models, methods (Hevner et al. 2004; March and Smith 1995) and better theories (Rossi and Sein 2003). Constructs define the conceptual vocabulary of a domain, models contain an expression of how constructs are related, methods provide a description on how to perform a specific task, and better theories are derived from experiment-like proof of concept. To address these needs, the theme of this working conference incorporates issues related to the integration and cross-fertilization of DSR with the organizational and societal research areas traditionally covered by IFIP Working Groups 8.2 (Information Systems and Organizations) and 8.6 (Diffusion, Transfer, and Implementation of Information Technology).

\section{THIS BOOK}

This book is the result of the IFIP WG 8.2/8.6 Joint International Working Conference on Human Benefit Through the Diffusion of Information Systems Design Science 
Research, held in Perth, Western Australia, March 30-April 1, 2010. This chapter introduces the theme of the conference and provides an overview of the research contributions that are included in the book. While not all of the issues mentioned above are explicitly addressed by the papers selected for these Proceedings, the breadth and variety of the research and ideas presented represent a major step forward in our understanding of the design, development, adoption, and diffusion of IT/IS artifacts that can provide human benefits.

In this book, we have grouped the papers into six areas. The first part looks at design, organization, and adoption. The second part we have called design exemplars. The third part discusses the notion of human benefit. The fourth part is about designing adoption and diffusion. The fifth part looks at the core of DSR and discusses design as science. And the sixth part focuses on participation in design. Finally, at the end of the book we have included three panels descriptions.

\section{Part 1: Design, Organizations, and Adoption}

The first part of the book aims exactly at the area of overlapping interest between the two Working Groups that have responsibility for this conference. IFIP WG 8.2 looks at organizations and information systems and IFIP WG 8.6 looks at diffusion and adoption of information technology.

In Chapter 2, Dirk Hovorka aims at expanding DSR into the broader organizational and societal research domains. "Care must be taken," says Hovorka, to comprehend and articulate the philosophical underpinnings of theory building and evaluation in DSR, or we will end up creating incoherent design theory. The approach suggested by Hovorka is a so-called multi-paradigm grounding to ensure that the DSR approach remains a legitimate approach to knowledge creation.

Mutaz Al-Debei and Guy Fitzgerald look more specifically at design problems in mobile data services. In Chapter 3, they develop an ontology based on business model thinking. The research approach to building the ontology essentially follows the designscience paradigm but also incorporates other research methods. The developed ontology identifies four primary dimensions in designing business models for mobile data services: value proposition, value network, value architecture, and value finance. Within these dimensions, 15 key design concepts are identified along with their interrelationships and rules. The resulting ontology is of value to academics and practitioners alike, particularly those interested in strategy and telecommunication in relation to IS.

In Chapter 4, Heidi Tscherning and Lars Mathiassen present detailed insights into why and how five closely related individuals decided to adopt the iPhone before it was available through traditional supply chains. Discussing the role played by social networks, Tscherning and Mathiassen analyze how adoption threshold, opinion leaders, social contagion, and social learning shape adoption. The chapter confirms that network structures in fact have an impact, and it shows that the adoption decisions emerged as a combined result of individual adoption reflections and major influences from the social network. 


\section{Part 2: Design Exemplars}

An exemplar is a model or pattern to be copied or imitated. The second part of this book contains three very interesting exemplars of design.

In Chapter 5, Ivan Aaen asks, "How can we facilitate innovative software development in teams?" He comes up with an answer in the form of a work-in-progress design called Essence made with inspiration from role-play and improvisational theater. Based on agile principles, Essence is designed for teams of developers and an onsite customer. Essence has been applied in teaching at Aalborg University, where different roles were assigned to team members. This provided valuable insights into the design of roles in Essence. These insights were then used for redesigning the roles in Essence, thereby emphasizing the iterative nature of DSR.

In Chapter 6, Michael Hicks, Graham Pervan, and Brian Perrin explore the criteria of effective IT governance processes employed in universities and their impact on the diffusion of appropriate technology to users. A case study was conducted at a large Australian university that is currently undergoing a major restructure of its IT governance process. The case study found significant improvement in key areas of IT governance and the University realized that IT governance is an ongoing design process.

In Chapter 7, Carl Lawrence, Tuure Tuunanen, and Michael Myers propose an extension of DSR by integrating critical ethnography into the evaluation phase. Critical ethnography provides a way for IS researchers using DSR to better understand culture, and may help to ensure that IT artifacts are designed for a variety of cultural contexts. This is a very important theme to discuss, as the creation and design of artifacts lies at the heart of DSR. However, with an increasingly connected and globalized world, designing IT artifacts for a multicultural world is a challenge. This chapter offers a way to do so.

\section{Part 3: Human Benefit?}

Is there human benefit from design? This was the key question we raised when we gave the name to this conference. In this part of the book, three chapters discuss that question from three quite different angles.

Imran Khan and Elaine Ferneley, in Chapter 8, look at the UK National Health Service, which is currently is undergoing tremendous IS led change. In the concrete, the case presented is about the design of an electronic single patient care record system. The chapter examines the extent to which persuasive discourse, or rhetoric, influences and affects the adoption of IS. Further, the chapter explores the ways in which various actors use rhetoric to advance their own agendas and the impact this has. The chapter concludes that rhetoric is an important and effective persuasive tool, employed by system trainers to coax users into not only adopting the system but also into using the system in a predefined manner.

Chapter 9 by Ramanjit Singh and Trevor Wood-Harper is a study of the challenges faced by knowledge workers in a Swedish company TeliaSonera when using wireless technology on the move. The chapter identifies five problem areas: (1) work and life 
balance, (2) addiction, (3) organizational involvement, (4) nomadic work and control, and (5) individual productivity. Each problem area is subsequently analyzed using sociotechnical design principles. The chapter concludes that better role boundary management, self-discipline, work negotiation, and e-mail communication skills may be required for the knowledge workers to manage the demands of nomadic working.

In Chapter 10, Mikael Lind, Daniel Rudmark, and Ulf Seigerroth look at the design of business processes in another Swedish company, Intersport. The study was carried out as an action research undertaking where the purpose was to design a new process aligned with the strategic goals of Intersport. The chapter address the question of how design science research can contribute to business process design. Three heuristic guidelines for creating organizational commitment and strategic alignment in process design are presented - derived from successful actions taken. Finally these guidelines are used as a basis to reflect on the contribution of DSR in relation to business process design.

\section{Part 4: Designing Adoption}

This part of the book contains four papers of a more classic WG 8.6 nature in that they have adoption as their primary topic. In all four chapters we can, however, find elements of design, hence the title for this part: designing adoption.

In Chapter 11, Mohammad Hossain and Mohammed Quaddus look at the adoption process and the subsequent diffusion and extended usage of RFID (radio frequency identification) for Australian livestock. A research model is designed based on Rogers' innovation-diffusion theory and Oliver's expectation-confirmation theory. The model posits that while adoption of RFID may result from legislative pressure, its further diffusion is an evaluative process, which is judged against "satisfaction" and "performance" derived from RFID systems. The implications of the designed model are then discussed and some hypotheses developed.

In Chapter 12, Yogesh Dwivedi, Navonil Mustafee, Michael Williams, and Banita Lal examine the factors affecting the consumer adoption of broadband in the UK. A conceptual model of broadband adoption is designed by selecting and justifying a number of relevant constructs from the technology adoption literature. Findings from the testing of the model suggest that relative advantage, utilitarian and hedonic outcomes, primary influence, facilitating conditions, resources, and self-efficacy all have an influence. The potential implication of this chapter is that stakeholders in broadband adoption can use the findings to encourage and promote the adoption and usage of broadband among the general population in the UK as well as in other parts of the world.

In Chapter 13, Gasparas Jarulaitis takes a closer look at the adoption of Microsoft SharePoint in a global oil company. Longitudinal data from the period 2007-2009 are analyzed focusing on two parts of the organization, $R \& D$ and oil and gas production. As a result, Jarulaitis found that the different ways in which the technology is managed and used in these contexts results in uneven diffusion.

Chapter 14 concludes this part of the book with an analysis by Yogesh Dwivedi, Linda Levine, Michael Williams, Mohini Singh, David Wastell, and Deborah Bunker of the research published in the previous 11 IFIP WG 8.6 conferences held between 1993 
and 2008. Their analysis of the published material includes examining variables such as the most active authors, citation analysis, universities associated with the most publications, geographic diversity, and authors' backgrounds. The keyword analysis suggests that the work in WG 8.6 has evolved from examining basic issues such as organizational impact of technology adoption and technology transfer to contemporary issues such as open innovation.

\section{Part 5: Design Science}

This fifth part of the book returns to design as a science. Three interesting approaches are given, spanning from situational design to designing management.

In Chapter 15, Daniel Stock, Robert Winter, and Jörg Mayer lay the foundation for the design of a situational method for functional service domain architecture management. Based on a review of current literature, a framework is proposed. In this framework, the authors find that situational method engineering for functional domains can be applied by identifying context types and goal vectors, designing fragments, and associating successfully adopted method fragments with specific situations. Finally, the validity of the proposed framework is tested by five case studies.

In Chapter 16, Jan Pries-Heje and Richard Baskerville elaborate a DSR approach for management planning anchored to the concept of a management design theory. Unlike the notions of design theories arising from information systems, management design theories can appear as a system of technological rules, much as a system of hypotheses or propositions can embody scientific theories. This chapter illustrates this form of management design theories with three grounded cases: process improvement, user involvement, and organizational change.

In Chapter 17, Colin Armstrong and Helen Armstrong present an overview of the application of DSR to the management of forensic evidence processing. The chapter begins with a discussion of DSR and socio-technical IS research in relation to the processing of forensic evidence. The discussion then presents the current problems faced by those dealing with evidence and a conceptual meta-model for a unified approach to forensic evidence is developed. Finally, Armstrong and Armstrong state that practical application of the suggested model would have to be predominantly driven by law enforcement.

\section{Part 6: Participation in Design}

The this sixth part of the book, another theme at the core of design, namely, participation, is examined. Again we have three chapters. These span from a look at agile methods, through a living laboratory with users, to design of airport security.

In Chapter 18, Karlheinz Kautz provides a case study of a large agile development project and focuses on how customers and users participated in agile development and design activities in practice. The investigated project utilized the agile method eXtreme Programming. Planning games, user stories and story cards, working software, and 
acceptance tests structured the customer and user involvement. Kautz finds genuine customer and user involvement in the design activities in the form of both direct and indirect participation in the agile development project. Further, the involved customer representatives played informative, consultative, and participative roles in the project. This led to their functional empowerment: the users were enabled to carry out their work to their own satisfaction and in an effective, efficient and economical manner.

In Chapter 19, Birgitta Bergwall-Kåreborn, Debra Howcroft, Anna Ståhlbröst, and Anna Wikman employ a case study using a "living lab." The starting point is taken in the observation that while participation is established and has been reported successful in many cases, some now see it as an "old, tired concept" that is in need of revitalization in order to cater for changing IS practices. Thus the authors look at the process of participation during the design stages of a health care project for the elderly in Sweden. In this chapter, Bergwall-Kåreborn et al. reflect on how participation materializes in a context that is quite dissimilar from more traditional development settings and report on the kinds of practices that may be used to assist design with users

In Chapter 20, Thomas Østerlie, Ole Martin Asak, Ole George Pettersen, and Håvard Tronhus describe a study of ICT use at an airport security checkpoint to explore the paradox that travelers find existing airport security measures inadequate while at the same time believing air travel to be sufficiently secure. Østerlie et al. pursue this paradox by showing that for the security checkpoint to function properly in relation to the overall

function of the airport, travelers have to be enrolled in a particular program of action, one in which travelers are both ethically and morally challenged (in their own view). Nevertheless, their active participation makes it difficult for them to object to the moral and ethical issues. Thus the explanation for the paradox presented is that travelers have been made accomplices.

\section{References}

Baskerville, R., Pries-Heje, J., and Venable, J. 2007. "Soft Design Science Research: Extending the Boundaries of Evaluation in Design Science Research," in Proceedings of the $2^{\text {nd }}$ International Conference on Design Science Research in Information Systems and Technology (DESRIST 2007), S. Chatterjee and M. Rossi (eds.), Pasadena, California, USA, May 13-15.

Baskerville, R., Pries-Heje, J., and Venable, J. 2009. "Soft Design Science Methodology," in Proceedings of the $4^{\text {th }}$ International Conference on Design Science Research in Information Systems and Technology (DESRIST 2009), S. Purao, K. Lyytinen, and I-Y. Song (eds.), Philadelphia, Pennsylvania, USA, May 7-8 May.

Boland, R. J. 2002. "Design in the Punctuation of Management Action," paper presented at the Workshop on Managing as Designing, Weatherhead School of Management, Case Western Reserve University, Cleveland, Ohio, June 14-15 (available online at http://design.case.edu/ 2002workshop/index.html; accessed June 17, 2004).

Bunker, D., and Campbell, J. 2005. "A Perspectival Punctuated Action Approach to Policy Development in Information Technology and Systems" in Proceedings of the $16^{\text {th }}$ Australasian Conference on Information System, Sydney, Australia, November 29-December 2 (available online at http://aisel.aisnet.org/; accessed December 31, 2009). 
Hevner, A. R., March, S. T., Park, J., and Ram, S. 2004. "Design Science in Information Systems Research," MIS Quarterly (28:1), pp. 75-106.

Iivari, J., and Venable, J. 2009. "Action Research and Design Science Research-Seemingly Similar But Decisively Dissimilar," in Proceedings of the 2009 European Conference on Information Systems, Verona, Italy, June 8-10, pp. 2711-2723.

Klein, H. K., and Kumar, K. (eds). 1989. Proceedings of the IFIP WG 8.2 Working Conference on Information Systems Development for Human Progress in Organizations (Atlanta, Georgia, May 29-31, 1987), Amsterdam: North-Holland.

March, S., and Smith, G. 1995. "Design and Natural Science Research on Information Technology," Decision Support Systems (15:4), pp. 251-266.

Nunamaker, J. F., Jr., Chen, M., and Purdin, T. 2001. "Systems Development in Information Systems Research, Journal of Management Information Systems (7:3), pp. 89-106.

Orlikowski, W. J., and Iacono, C. S. 2001. "Research Commentary: Desperately Seeking the 'IT' in IT Research-A Call to Theorizing the IT Artifact," Information Systems Research (12:2), pp. 121-143.

Rossi, M. and Sein, M. 2003. "Design Research Workshop: A Proactive Research Approach," presentation delivered at the $26^{\text {th }}$ Information Systems Research Seminar in Scandinavia /(IRIS 26), August 9-12.

Simon, H. A. 1977. The New Science of Management Decision (revised edition), Englewood Cliffs, NJ: Prentice Hall.

Simon, H. A. 1996. The Sciences of the Artificial (3 ${ }^{\text {rd }}$ ed.), Cambridge, MA: The MIT Press.

Ulrich, W. 1981. Critical Heuristics of Social Planning: A New Approach to Practical Philosophy., Bern: Paul Hapt.

Ulrich, W. 1987. "Critical Heuristics of Social Systems Design," European Journal of Operational Research (31), pp. 276-283.

Ulrich, W. 2002. "A Mini-Primer of Critical Systems Heuristics," in The Informed Student Guide to Management Science, H. G. Daellenbach and R. L. Flood (eds.), London: Thomson Learning, p. $72 \mathrm{f}$.

Vaishnavi, V., and Kuechler, W. 2004. "Design Research in Information Systems," IS World/ Association for Information Systems (available online at http://desrist.org/design-researchin-information-systems/).

Venable, J. R. 2006. "The Role of Theory and Theorising in Design Science Research," in Proceedings of the First International Conference on Design Science Research in Information Systems and Technology, A. Hevner and S. Chatterjee (eds.), Claremont Graduate School, Claremont, CA, February 24-25.

Venable, J. R. 2009. "Identifying and Addressing Stakeholder Interests in Design Science Research: An Analysis Using Critical Systems Heuristics," Proceedings of the IFIP WG 8.2 Working Conference on the Tole of IS in Leveraging the Intelligence and Creativity of SME's (CreativeSME), Guimarães, Portugal, June 21-24, Berlin: Springer, Berlin, pp. 93-112.

Walls, J. G., Widmeyer, G. R., and El Sawy, O. A. 1992. "Building an Information System Design Theory for Vigilant EIS," Information Systems Research (3:1), pp. 36-59.

Weber, R. 2003. "Editor's Comments: Still Desperately Seeking the IT Artifact," MIS Quarterly (27:2), pp. iii-xi.

\section{About the Authors}

John Venable is an associate professor and former Head of School at the School of Information Systems, Curtin University of Technology. He received a Ph.D. in Advanced 
Technology (Information Systems) from Binghamton University (New York) in 1994. He has taught and researched in IS at Binghamton University and Central Connecticut State University in the United States, at Aalborg University in Denmark, at the University of Waikato in New Zealand, and at Murdoch University and Curtin University of Technology in Australia. He has consulted on ICT and organizational change with large and small business organizations, government agencies, and not-for-profit organizations. His main research interests are in IS development and planning methods and practice, modeling of organizations, IS and data, problem solving methods, organizational change, group support systems, knowledge management and organizational learning, IS in the not-for-profit sector, and IS research methods, including critical research and design science research. John can be reached by e-mail at John.Venable@, cbs.curtin.edu.au.

Jan Pries Heje is a professor in Information Systems, Department of Communication, Business and Information Technologies, Roskilde University, and head of the User Driven ITInnovation Research Group. His research focuses on designing and building innovative solutions to managerial and organizational IT problems. Previous and current projects explore process improvement as design, the ability for an organization to improve, and how one can design a process for making better sourcing decisions. From January 2010, Jan is the Chair of the IFIP Technical Committee 8 on Information Systems. He can be reached by e-mail at janph@ruc.dk.

Deborah Bunker is a senior lecturer in the discipline of Business Information Systems at the University of Sydney in Australia. She holds a Ph.D. in Information Systems Management. Her research interests are in IS management frameworks and approaches, IS innovation, adoption and diffusion, interorganizational IS and philosophical foundations of IS (phenomenology, systems thinking, system of systems) and she has published widely in these areas. Deborah is president of the Australasian Association of IS (AAIS) and is a founding member and the current Vice Chair of IFIP WG 8.6 on the adoption and diffusion of IT. She can be reached by e-mail at D.Bunker@econ.usyd.edu.au.

Nancy L. Russo is the Pavlović Professor of Information Systems in the Department of Operations Management \& Information Systems at Northern Illinois University. She also serves as the Vice-Rector for International Cooperation at Slobomir P University in Bosnia \& Herzegovina. She received her Ph.D. in Management Information Systems from Georgia State University in 1993. Her research has addressed the use and customization of system development methods, factors related to information systems success, IT innovation, and issues related to research and education in the information systems field. Her work has appeared in Information Systems Journal, European Journal of Information Systems, Information Technology \& People, Journal of Information Technology, and other international journals and conference proceedings. Nancy is currently the Chair of IFIP WG 8.2. She can be reached by e-mail at nrusso@niu.edu. 